\title{
TERRORISMO MARÍTIMO Y LIBERTAD \\ DE NAVEGACIÓN. LA ACTIVIDAD DE LA ORGANIZACIÓN MARÍTIMA INTERNACIONAL EN MATERIA DE PROTECCIÓN \\ Y LOS CLAROSCUROS DEL CONVENIO SUA Y DEL PROTOCOLO SUA DE OCTUBRE DE 2005
}

\author{
David ENRÍQUEZ*
}

RESUMEN: El presente artículo analiza la actividad de la OMI en el campo de protección marítima y dentro del principio de la libertad de la navegación de la Convemar de 1982. En especial se estudian algunas normas especialmente controvertidas de los instrumentos SUA de 2005 sobre terrorismo marítimo. Se argumenta que algunas de las normas del nuevo tratado podrán llevar a abusos de las autoridades extranjeras respecto a embarcaciones, tripulantes y cargas, cuando se ejecuten inspecciones en alta mar.

ABSTRACT: This article analyses the activities by IMO in the field of maritime security and within the principle of freedom of navigation established in UNCLOS 1982. In particular, some especially controversial rules of the SUA instruments 2005 on terrorism are studied. It is argued that some of the rules of the new treaty may lead to the abuse by foreign authorities to vessels, crewmembers and cargoes when executing inspections at the high seas.

RÉSUMÉ: L'article analyse l'activité de la OMI matière de protection maritime et par rapport au principe de la liberté de navigation de la Convemar de 1982. On étudie, de manière particulier, des règles qui ont généré des controverses, ces règles sont des instruments de la SUA de 2005 sur le terrorisme maritime. On argumente que certaines règles du nouveau Traité pourraient donner lieu à des abus de la part des autorités étrangères para rapport à des bateaux, à l'équipage et au chargement, lors des visites d'inspection en Haute mer.

* Doctor en derecho, investigador nacional nivel I del SNI e investigador del Instituto Panamericano de Jurisprudencia. El autor fungió como miembro de la delegación de México durante la negociación de los protocolos SUA. 
SUMARIO: I. Introducción. II. La evolución del principio sobre la libertad de navegación. III. La Organización Maritima Internacional frente al terrorismo. IV. Los instrumentos SUA de octubre de 2005 y el combate al terrorismo internacional. Claroscuros de la negociación y consecuencias del nuevo régimen. V. Comentarios finales.

\section{INTRODUCCIÓN}

El secuestro del crucero italiano Achille Lauro por una célula de la Organización para la Liberación Palestina (OLP) en octubre de 1985 se convirtió en el catalizador más importante de la actividad moderna en materia de protección, por parte de la Organización Marítima Internacional (OMI). Sin embargo, fueron los actos terroristas perpetrados en territorio estadounidense el 11 de septiembre de 2001 los que dieron un verdadero vuelco en la agenda de prácticamente todos los organismos internacionales con el claro rumbo de la protección integral. ${ }^{1}$ La OMI no solamente no ha sido la excepción a esta dinámica, sino que se ha convertido indudablemente en una de las entidades más activas en su fomento. ${ }^{2}$

En efecto, en virtud de resoluciones tanto de la Organización de las Naciones Unidas (ONU) como de la propia OMI, en las cuales se condenan todas las formas de terrorismo, como el del llamado 9-11, la organización se ha abocado a trabajar sobre tres expedientes específicos que inciden en esta asignatura. Me refiero respectivamente a: a) El Código Internacional para la Protección de los Buques y de las Instalaciones Por-

1 Véase Vogelson, Jay, "Multinational approaches to eradicating international terrorism", The International Lawyer, núm. 36-67, primavera de 2003. Como explica el autor, si bien las iniciativas de protección — primero regional y después universal - en la lucha contra el terrorismo iniciaron desde la constitución misma de la OTAN y más tarde a través de organismos técnicos como OACI en materia de protección aeronáutica en la Convención de Tokio de 1963, el verdadero abanico de protección contra el terrorismo en todos los frentes inició a partir del 9-11.

2 Como desarrollo más adelante, la actividad de la OMI no es en absoluto nueva. Sin embargo, la profundización de su actividad se ha centrado a partir del 9-11 en instrumentos obligatorios y no en simples circulares recomendatorias. Una descripción acuciosa de las actividades de la OMI en protección puede verse en un artículo de la directora de la División Legal y de Relaciones Internacionales de la OMI. Véase Balkin, Rosalie, "The International Maritime Organization and Maritime Security", Tulane Maritime Law Journal, núm. 30-1, invierno-verano de 2006. 
tuarias (Código PBIP) de 2002; b) Los protocolos de enmienda al Convenio para la Represión de Actos Ilícitos contra la Seguridad de la Navegación Marítima de 1988, así como al Convenio para la Represión de Actos Ilícitos contra las Plataformas Fijas Emplazadas en la Plataforma Continental de 1988 (conocidos respectivamente como Convenio SUA y Protocolo SUA sobre Plataformas Fijas) de 2005; y c) El Sistema de Seguimiento de Largo Alcance (Sistema LRIT) de 2006.

Si bien el Código PBIP y el Sistema LRIT articulan una serie de normas de naturaleza primordialmente técnica para la protección de las embarcaciones, los artefactos navales e incluso las instalaciones portuarias con el fin de prevenir ataques terroristas - y en caso de ocurrir éstos, estar en aptitud de responder con eficacia y prontitud-, el convenio y protocolo SUA de 2005 son instrumentos de carácter primordialmente procesal, a partir de los cuales se ejercen actos de autoridad de Estados a bordo de embarcaciones de terceros países tanto en el alta mar como incluso, en la zona económica exclusiva.

En el presente artículo, pretendo precisamente enfocarme en algunos rasgos de interés de los instrumentos SUA 2005. Para ello, propongo en primer lugar recordar el contenido e importancia de un principio que, aunque existente todavía, nunca ha sido tan radicalmente acotado: la libertad de navegación. ${ }^{3}$ En un segundo momento, pretendo comentar los principales esfuerzos de la OMI en materia de protección de la navegación a lo largo de las últimas dos décadas. Por último, en el ámbito de este segundo periodo de actividades, procuraré destacar los aspectos más relevantes - y conflictivos - de los instrumentos SUA 2005, así como la participación que tuvo la delegación mexicana en su negociación, en la cual tuve la responsabilidad y gusto de participar.

Como se advertirá a lo largo de estas líneas, estamos situados frente a dos bienes jurídicos tutelados - la libre navegación internacional y la protección de personas y bienes ante la omnipresente amenaza terrorista- y un importante reto por lograr: la armonización de ambos, de modo que la efectiva protección no represente un retroceso a la legítima libertad

3 Véase Convención de las Naciones Unidas sobre el Derecho del Mar de 1982 (Convemar), arts. 192-194 y 211 (6). 
de navegación; una de las primordiales conquistas del derecho del mar, lograda tras siglos de guerras, debates y negociaciones internacionales. ${ }^{4}$

\section{LA EVOLUCIÓN DEL PRINCIPIO SOBRE LA LIBERTAD DE NAVEGACIÓN}

\section{Antecedentes}

El principio de la libertad de los mares, en el cual se encuadra el concepto normativo actual conocido como la libertad de navegación, es uno de los pilares de la evolución del derecho internacional. Su importancia es tal, que sin su efectiva aplicación sería imposible pensar en el comercio marítimo en el que se sustenta una parte importante de la economía mundial. ${ }^{5}$

Mientras que la Antigüedad Occidental se caracterizó por la imposición exclusiva del ejercicio de la navegación entre los pueblos conquistadores, como en su momento lo fueron los fenicios, los cartagineses o los helenos respecto al Mediterráneo, la era de la paz romana tuvo por primera vez en cuenta el criterio de juristas, entre ellos Ulpiano y Celso, quienes atribuían una connotación de uso común a los espacios marítimos. ${ }^{6}$

Desde luego, la interpretación que los gobernantes romanos daban a los criterios de sus jurisconsultos no podía tener otra dimensión que la de

4 Para una introducción al estudio del derecho del mar véase, entre otros: Cervera, José, El derecho del mar, Madrid, Naval, 1992, pp. 37 y ss.; Gómez-Robledo, Alonso, Derecho del mar, México, UNAM, Instituto de Investigaciones Jurídicas, pp. 105 y ss.; Szekely, Alberto, Derecho del mar, México, UNAM, Instituto de Investigaciones Jurídicas, 1991, pp. 27 y ss.; Scovazzi, Tullio, Elementos de derecho internacional del mar, Madrid, Tecnos, 1994, pp. 55 y ss.; Sobarzo, Alejandro, Régimen jurídico del alta mar, México, Porrúa, 1985, pp. 55 y ss.; Castañeda, Jorge, Obras completas. Derecho del mar, México, IMRED, 1995, pp. 101 y ss.; Enríquez, David, Historia del derecho marítimo mexicano, Colima, Gobierno del Estado de Colima, 1997, pp. 2 y ss.

5 Véase el debate histórico sobre el principio de la libertad de los mares, consagrado hoy en la Convemar, art. 87, en Grocio, Hugo, De la libertad de los mares, trad. de Blanco García y García Arias, Madrid, Civitas, 1979, pp. 53 y ss.; Fulton, Thomas, The Sovereignty of the Sea, Londres, Pitman, 1911, pp. 17 y ss.; García, Luis, Historia del principio de la libertad de los mares, Santiago de Compostela, 1948, pp. 9 y ss.; Enríquez, David, "La libertad de navegación", Revista Jurídica Jalisciense, Guadalajara, enero-abril de 1997.

6 Véase D. 8.4.13 y D. 43.8 .3 
garantizar el libre ejercicio de la navegación al interior del propio Imperio Romano, con lo cual, la vigencia del principio de la libertad de los mares entre distintas jurisdicciones, es en esta época, naturalmente cuestionable.

Con la caída del Imperio Romano y la consolidación de prósperas ciudades-Estado durante la Edad Media, creció la confrontación entre potencias marítimas, como Venecia o Génova, que buscaban reclamar derechos exclusivos sobre zonas marinas estratégicas para sus intereses comerciales. Conflictos similares emergieron no sólo en el Mar Mediterráneo sino también en los mares Báltico y del Norte; en donde Suecia, Dinamarca e Inglaterra buscaban tomar el control de las rutas internacionales.

Fue sin duda el inicio de la época de la colonización la que llevó al punto más alto la discusión sobre la primacía en los mares. En ella, las pretensiones de las coronas aumentaban en proporciones desconocidas hasta el momento: España reclamaba derechos exclusivos sobre el Océano Pacífico y el Golfo de México, y Portugal sobre los océanos Índico y Atlántico Sur. ${ }^{7}$

\section{La batalla libresca}

Si bien la causa del estudio más famoso por la defensa de la libertad de los mares, no fue necesariamente académica o altruista, no queda duda que elevó el debate, de una simple discusión política y militar entre potencias marítimas, a un verdadero debate jurídico entre pensadores, que a la postre influiría en la consolidación del derecho internacional del mar. Me refiero a la obra de Hugo Grocio, conocida como Mare Liberum de $1605 .{ }^{8}$

7 Las disputas por el control de los mares son, sin duda, cuna del derecho internacional. Si bien la jerarquía que éstas cobraron en la evolución del derecho internacional escapa al objeto de este trabajo, son recomendables entre otros muchos estudios: Basave, Agustín, Filosofía del derecho internacional, México, UNAM, Instituto de Investigaciones Jurídicas, 1992, pp. 238 y ss.; Sorensen, Max, Manual de derecho internacional público, México, FCE, 1968, pp. 344 y ss.; Sepúlveda, César, Derecho internacional, México, Porrúa, 1991, pp. 463 y ss.

8 La obra, cuyo título completo es originalmente Mare liberum sive de jure quod Batavis competit ad Indicana comercia dissertatio es realmente uno de los capítulos del De iure praede commentarius en el cual Grocio argumentaba a favor de la Compañía Holandesa de Indias Orientales, quien a su vez buscaba convencer a sus accionistas 
En esencia, Mare Liberum fue una interesante argumentación escrita contra Portugal, publicada en oposición a España y utilizada en detrimento de Inglaterra por comerciantes marítimos holandeses, quienes lejos de defender los postulados filosóficos de la libertad de los mares - cuya auténtico fundamento fue realmente labrado por los intelectuales españoles Francisco de Vitoria y Fernando Vázquez de Menchaca, medio siglo atrás - pretendían tener acceso a mejores tráficos y abundantes caladeros en los mares de sus vecinos.

Así, mediante la sistematización de los postulados de Vitoria y Vázquez de Menchaca, el edificio argumentativo del joven Grocio descansó en tres pilares, bien expuestos por Luis García con la redacción propia del texto original: ${ }^{9}$

En virtud del ius communicationis, los hispánicos no pueden prohibir a los holandeses el acceso a las Indias Orientales debido a: (i) no tener los lusitanos soberanía sobre la India, ni poder presentar a su favor títulos legítimos, que no pueden basarse en el ius inventionis, la donación pontificia o el ius belli; (ii) no tener dominio sobre el mar o sobre la navegación ni por descubrimiento u ocupación, ni por donación pontificia, ni por prescripción o costumbre adquisitiva; y (iii) no tener derecho a impedir el comercio, que es libre por derecho de gentes, ni por ocupación, ni por donación pontificia, ni por prescripción o usucapión, ni por motivos de equidad. Por consiguiente, los holandeses deben mantener el comercio con las Indias orientales, sea en paz, en tregua o en guerra, contra quien se oponga.

La famosa obra de Grocio dio lugar a uno de los debates más interesantes generados en el derecho internacional, la llamada Gran batalla libresca, una polémica intelectual — con dimensiones políticas e incluso

menonitas de aceptar los beneficios económicos de la carraca portuguesa "Catalina" apresada en el litoral de la Península de Malaca en el Sudeste Asiático por el Almirante Heemskerk en 1602. La obra fue escrita entre 1604 y 1605 cuando su autor contaba sólo con veinte años de edad. Véase García, Luis, "Prólogo", en Grocio, Hugo, op. cit., nota 5, pp. 10 y ss. Véase también Brown, James, "La gènese du Traitè du Droit de la Guerre et de la Paix", Revue de Droit International et de Législation Comparée, Bruselas, 1925, t. VI, pp. 489 y ss.

9 Véase García, Luis, op. cit., nota 5, pp. 10 y ss. El autor hace una excelente relación de los autores, obras y sentidos argumentativos de la famosa polémica libresca protagonizada durante buena parte del siglo XVII. 
bélicas - entre juristas de diversas nacionalidades, quienes defendían en uno y otro sentido la libertad o la exclusividad de los mares.

Si bien dentro de su contexto se redactaron documentos influyentes como los de William Welwood o fray Serafín de Freitas, sería hasta 1618 en que el inglés John Seldein escribiría De dominio maris regio, publicado en 1635 bajo el título polémico de Mare clausum, en donde en oposición al Mare liberum de Grocio, argumentaría brillantemente desde una perspectiva histórica a favor de la política exclusivista inglesa sobre los mares. ${ }^{10}$

Como acertadamente explica Alejandro Sobarzo, la semilla echada por Grocio cayó en tierra fértil. A pesar de los vaivenes de la argumentación y la presión política entre las potencias marítimas, la balanza se inclinaría claramente hacia el principio de la libertad de los mares en oposición a la pretendida exclusividad de diversas potencias, en especial Inglaterra.

Así las cosas, otro holandés, Cornelio Van Bynkershoek, concluiría en 1702 con un siglo de discusiones mediante la publicación de su estudio, De dominio maris dissertatio, en el cual esbozaría la realidad en un principio: la potestad terrestre termina donde termina la fuerza de las armas. Con ello, la división entre el mar territorial y el alta mar tenía una sola medida efectiva: la de la fuerza de los cañones en batalla. ${ }^{11}$

\section{La Convención de las Naciones Unidas sobre el Derecho del Mar}

Finalmente, ya en el primer cuarto del siglo XIX, el equilibrio de potencias marítimas generado por la consolidación de grandes ejércitos en tierra hizo incuestionable el principio de la libertad de los mares. Sin embargo, faltaría todavía un siglo y medio más para quedar consagrado en el instrumento más importante y ampliamente sancionado en la historia del derecho del mar: la Convención de las Naciones Unidas sobre el Derecho del Mar de Montego Bay, Jamaica, de 1982 (Convemar), en donde

10 Idem. Véase también Fulton, Thomas, The Sovereingty of the Sea, Londres, Pitman, 1911, pp. 346 y ss.

11 A lo largo de las negociaciones por unificar las pretensiones sobre derechos exclusivos en la alta mar, se llegó por fin en la Convemar de 1982 al consenso consistente en que todo Estado tiene derecho a establecer la anchura de su mar territorial hasta un límite que no exceda de 12 millas marinas medidas a partir de líneas de base determinadas de conformidad con la propia convención. Convemar, artículo 3. 
se establece de una vez y para siempre, que ningún Estado podrá pretender legítimamente someter cualquier parte de la alta mar a su soberanía. ${ }^{12}$

En efecto, harían falta tres conferencias de las Naciones Unidas sobre Derecho del Mar para dotar de validez formal plena a la libertad de navegación. Con un trabajo iniciado en 1949 por la Comisión de Derecho Internacional de las Naciones Unidas y desarrollado a lo largo de más de tres décadas hasta la Convención de Jamaica, la libertad de navegación debe entenderse como uno de los seis derechos reconocidos por la Convemar a sus Estados miembros.

Así, de acuerdo con el artículo 87 de dicho instrumento internacional, libertad de navegación, libertad de sobrevuelo, libertad de tendido de cables y tuberías submarinos, libertad de construcción de islas artificiales y otras instalaciones permitidas por el derecho internacional, libertad de pesca y libertad de investigación científica constituyen la carta de derechos reconocidos a todos los Estados, sean éstos ribereños o sin litoral. La libertad en el ejercicio de los derechos mencionados en la alta mar está sujeta a los límites tanto de la propia Convemar, como de otras normas de derecho internacional; y debe siempre tener en cuenta los intereses de otros Estados en su ejercicio legítimo.

Asimismo, es conveniente recordar que la propia Convemar establece una serie de limitaciones a la libertad de navegación por motivos de protección del medio marino, seguridad de la navegación e incluso, por razones de protección, que desde luego son retomadas por el Convenio Internacional para la Seguridad de la Vida Humana en el Mar de 1974-78 (Convenio SOLAS), los instrumentos SUA 2005, etcétera. En mi opinión, el fundamento más importante de Convemar para el desarrollo de normas sobre protección marítima en otros tratados internacionales se encuentra en el artículo 92.1 relativo a la condición jurídica de las embarcaciones.

En efecto, como claramente señala el artículo de referencia, "Los buques navegarán bajo el pabellón de un solo Estado, y salvo en los casos de excepción previstos de modo expreso en los tratados internacionales o en esta convención, estarán sometidos, en la alta mar, a la jurisdicción exclusiva de dicho Estado". Como analizaré al comentar los contenidos de los instrumentos SUA 2005, el tratamiento para el caso de terrorismo marítimo es una evidente excepción a la jurisdicción exclusiva del Esta- 
do de bandera; siempre dentro de los límites establecidos por las normas de jurisdicción de los propios tratados que aquí comento.

\section{LA ORGANIZACIÓN MARÍTIMA INTERNACIONAL FRENTE AL TERRORISMO}

\section{Objetivos de la OMI en materia de protección marítima}

Es curioso caer en cuenta que el Convenio Constitutivo de la OMI no establece objetivos directos en materia de protección marítima. En efecto, las normas pertinentes señalan su facultad en torno a:

Alentar y facilitar la adopción general de normas tan elevadas como resulte factible en cuestiones relacionadas con la seguridad marítima, la eficiencia de la navegación y la prevención y contención de la contaminación del mar ocasionada por los buques; y atender las cuestiones administrativas y jurídicas relacionadas. ${ }^{13}$

A pesar de ello, y con adición a razones sobre costumbre internacional en la materia, lo cierto es que tanto el Convenio Constitutivo dispone de un alternativa para la actuación de la OMI, como la propia asamblea ha interpretado claramente la pertinencia para legislar en materia de protección marítima, como una derivación de la seguridad marítima. ${ }^{14}$ Así, dentro de los propios objetivos de la organización se le faculta para examinar toda cuestión que, en relación con la navegación marítima y los efectos de ésta en el medio marino, pueda serle sometida por cualquier órgano $\mathrm{u}$ organismo especializado de las Naciones Unidas. ${ }^{15}$ Es por ello que este objeto ampliado - o indirecto - se pone de manifiesto en un puñado de resoluciones sobre terrorismo, tanto de la propia OMI como de la Asamblea General de la ONU. Entre ellas:

13 Convenio Constitutivo OMI, artículo 1o. a).

14 Véase Balkin, Rosalie, op. cit., nota 2, p. 3; Becker, Michael, "The Shifting Public Order of the Oceans: Freedom of Navigation and the Interdiction of Ships at Sea", Harvard International Law Journal, núm. 46-131, invierno de 2005. En un interesante estudio, el autor expone los rasgos de política internacional que han presionado la elaboración y aplicación de instrumentos internacionales diseñados principalmente por EUA, y la ayuda de algunos de sus principales aliados como el Reino Unido.

15 Ibidem, d). 
a) La Resolución A.924 (22) de la Asamblea General de la OMI, de noviembre de 2001, en la que se pide que se revisen las medidas internacionales de carácter técnico y jurídico existentes, y se examinen otras nuevas con el objetivo de prevenir y reprimir los actos de terrorismo contra los buques y mejorar la seguridad a bordo y en tierra, reduciendo de ese modo los riesgos para los pasajeros, tripulaciones y personal portuario, tanto a bordo de los buques como en las zonas portuarias, así como para los buques y sus cargas.

b) La Declaración sobre Medidas para Eliminar el Terrorismo Internacional que figura en el anexo de la Resolución 49/60 de la Asamblea General de la ONU, de diciembre de 1994, en la que entre otras cosas, los Estados miembros reafirman que condenan en términos inequívocos todos los actos, métodos y prácticas terroristas, por considerarlos criminales e injustificables, dondequiera y por quienquiera sean cometidos, incluidos los que ponen en peligro las relaciones de amistad entre los Estados y los pueblos, y amenazan la integridad territorial y la seguridad de los Estados.

c) La Resolución 51/210 de la Asamblea General de la ONU de diciembre de 1996, así como la declaración complementaria de aquélla, de 1994, sobre medidas para eliminar el terrorismo internacional.

d) Las resoluciones 1368 (2001) y 1373 (2001) del Consejo de Seguridad de la $\mathrm{ONU}$, que reflejan la voluntad internacional de combatir el terrorismo en todas sus formas y manifestaciones en las que se asignan tareas y responsabilidades a los Estados, teniendo en cuenta la constante amenaza de ataques terroristas.

e) La Resolución 1540 (2004) del Consejo de Seguridad de la ONU en la que se reconoce la necesidad urgente de que todos los Estados adopten medidas eficaces de carácter adicional para prevenir la proliferación de armas nucleares, químicas y biológicas y de sus sistemas vectores.

Es pues claro que a pesar de que en los objetivos directos y expresamente señalados en el Convenio Constitutivo relativos a la seguridad marítima, la eficiencia de la navegación y la prevención y contención de la contaminación del mar, la OMI no parezca contar con facultades en materia de protección por rebasar su objeto, el propio Convenio Constitutivo, según lo antes señalado, da lugar a que la organización tramite solicitudes de otras instituciones internacionales. Además, resulta evidente que la protección fundamental de sus objetivos primarios no puede ser alcan- 
zada, de ocurrir ataques terroristas que vulneren el medio marino y la seguridad de la vida humana en el mar.

Una vez expresado lo anterior y antes de profundizar en algunos contenidos de los instrumentos SUA 2005, propongo referir brevemente y de forma temática las principales actividades normativas que la OMI ha desempeñado hasta antes del 9-11. Una vez hecho eso, haré una exposición sucinta de dos de los principales instrumentos post 9-11 antes sugeridos: el Código PBIP y el Sistema LRIT. En ocasiones, me permitiré hacer pequeños saltos de tiempo en cada epígrafe, con el fin de conservar el sentido práctico de la exposición. Finalmente, ahondaré en los instrumentos SUA 2005, y las controversias que en torno a ellos se han generado.

\section{Actividades generales de protección marítima de OMI.}

Una compilación temática de dos décadas de historia

\section{A. Fraude marítimo y actos de baratería}

A raíz de una solicitud del gobierno de Líbano a la Asamblea de OMI en noviembre de 1979, la organización incursionó en el tema del fraude marítimo y actos de baratería. Tras un estudio sobre el tema, un par de años más tarde se adoptó la Resolución A 504 (XII) en la cual se solicita a los Estados miembros la revisión de su legislación nacional y procedimientos de procuración de justicia con el fin de reprimir actos de baratería y fraude marítimo. Se pide de modo especial concentrarse en la adecuada administración de los registros navales, requisitos documentales, así como en la imposición de sanciones adecuadas para este tipo de actos.

El tema de la baratería y el fraude marítimo no debe entenderse simplemente en el ámbito de la delincuencia organizada de carácter ordinario, sino de modo extensivo dentro del conjunto de mecanismos financieros a través de los cuales, actualmente grupos terroristas pueden ser financiados. Así, la resolución citada de la OMI tiene hoy incluso mayor carta de naturalización en el contexto del Convenio Internacional para la Represión de la Financiación del Terrorismo, aprobado por la Asamblea General de la ONU en diciembre de $1999 .{ }^{16}$

16 Véase Fox, Bennett, "Vessel Ownership and Terrorism: Requiring Disclosure of Beneficial Ownership is not the Answer", Loyola Maritime Law Journal, núm. 4-92, 


\section{B. Piratería y robo armado}

A pesar que la piratería y el robo armado son actos milenarios que no pueden aislarse de la navegación misma, lo cierto es que su manifestación con el paso del tiempo es distinta, según puede observarse en los reportes mensuales de OMI. Además de las normas propias de la Convemar relativas a la piratería, el desarrollo normativo de la organización ha supuesto entre otras acciones, la adopción de la Resolución A.545 (13) en noviembre de 1983, en la cual se pretende vincular a los Estados miembros a mejorar sus sistemas de represión en sus aguas territoriales, incluidas las embarcaciones menores en tránsito y fondeadas en sus respectivas jurisdicciones. ${ }^{17}$

Años más tarde, en noviembre de 2001 se adoptó el Código para la Investigación de los Delitos de Piratería y Robo Armado en Contra de Buques, en el cual se reconoce que en algunas jurisdicciones el propio sistema de procuración de justicia es una barrera para la persecución y sanción de este tipo de delitos. Así, este código de naturaleza dispositiva para los Estados miembros es una guía para la adecuación de su legislación y aparato administrativo en la materia.

Sin duda, una de las mayores preocupaciones en materia de piratería es el Estrecho de Malaca en el sureste asiático. Este estrecho internacional ha sido por siglos azotado por piratas cada día de modo más complejo. El dato relevante en esta era de terrorismo no es en sí la piratería individualizada, sino lo sensible del blanco. Esto es, un ataque terrorista a

primavera de 2005. El autor analiza cómo la estructura misma de la propiedad de embarcaciones está articulada en el mercado de tal forma que el anonimato es en la práctica la regla general. Así, si bien se han tenido esfuerzos desde 1979 en esta materia, no es todavía sencillo en la mayor parte de las jurisdicciones dar con la identidad de los propietarios efectivos de la embarcación. Esto, con las repercusiones tanto fraudulentas como con las posibles consecuencias de financiamiento y utilización de embarcaciones para fines terroristas.

17 Véase Garmon, Tina, "International Law of the Sea: Reconciling the Law of Piracy and Terrorism in the Wake of September 11th", Tulane Maritime Law Journal, 27-257, invierno de 2002. La figura y el tratamiento jurídico de la piratería tal y como la conocíamos a lo largo de la historia de la navegación ha quedado rebasada. Este reconocimiento se encuentra tanto en los instrumentos SUA y el Código PBIP como en diversas resoluciones de la OMI y de otros organismos. La autora analiza esta nueva etapa en la regulación penal internacional a partir de la trascendencia de la piratería a los actos terroristas; todo en el contexto de la Convemar y el derecho internacional en general. 
una o varias embarcaciones en la zona, tendría por consecuencia la obstrucción del estrecho. En este sentido, valga recordar que más de 50,000 embarcaciones que transportan más de un $25 \%$ del comercio mundial transitan por el estrecho anualmente.

A partir de lo anterior, en noviembre de 2004 el Consejo de OMI solicitó al secretario general realizar las acciones de coordinación necesarias entre los Estados miembros de la región con el fin de garantizar el libre tránsito del Estrecho Internacional de Malaca. A raíz de ello y tras una serie de reuniones con los Estados ribereños - Indonesia, Malasia y Singapur - se ha elaborado el Proyecto de Carretera Electrónica Marina para el tráfico ordenado desde el punto de vista de la protección en la zona. Además, se comparte información, se realizan actividades de entrenamiento, creación de capacidad y cooperación técnica en general. Como puede verse, la situación del Estrecho de Malaca es un ejemplo claro de la trascendencia de la simple piratería al terrorismo global. ${ }^{18}$

\section{Sistema de asignación de un número OMI}

A raíz del estudio formulado originalmente respecto a baratería y fraude marítimo, la OMI con el apoyo de la Oficina Marítima de la Cámara Internacional de Comercio llegó a la conclusión en noviembre de 1985, que una de las formas más efectivas para evitar esas conductas habría de dirigirse hacia un sistema centralizado de asignación internacional de códigos permanentes. Así, un simple cambio del nombre del barco y la expedición de documentos falsos no habrían de ser ya suficientes para que los delincuentes tuvieran éxito en sus acciones.

En una versión ampliada del mecanismo voluntario para embarcaciones, a partir de la Resolución 160 (78) del Comité de Seguridad Marítima de OMI de mayo de 2004, se asignan incluso códigos a las navieras y a los propietarios de las embarcaciones a partir de 100 toneladas de registro bruto que estén dedicadas a tráficos de altura.

La eficacia del sistema se debe en buena medida a la participación del registro naval y de clasificación privado más influyente del mundo: Lloyd's Register-Fairplay, quien mantiene una base de datos con la his-

18 La preocupación por la situación de riesgo en el Estrecho de Malaca está documentada en muy diversos instrumentos tanto de la Asamblea General de la ONU en general, como en la OMI y en mecanismos asiáticos regionales. Entre ellos, véase U.N. Doc. A/RES/59/24 (febrero de 2005); IMO Doc. MSC/Circ 2659 (julio de 2005). 
toria completa respecto de la embarcación, en torno a las empresas involucradas en su propiedad y posesión. ${ }^{19}$

\section{Polizones, tráfico de personas, tráfico de drogas}

El tratamiento jurídico a las situaciones aludidas cuenta también con una trayectoria importante en la actividad de la organización, a través de su Comité de Facilitación, quien es el órgano encargado de facilitar el arribo y despacho de embarcaciones a los puertos de los Estados miembros. En efecto, las labores normativas de la OMI, particularmente en el tratamiento de polizones, han crecido a partir de la falta de éxito del tratado en la materia, elaborado por el Comité Marítimo Internacional (CMI) y adoptado en 1957. En este sentido, las guías elaboradas por el Comité de Facilitación y recogidas más tarde por la Resolución A.871 (20) de noviembre de 1997 de la asamblea, establecen mecanismos y procedimientos integrales para la repatriación de polizones en condiciones humanitarias, al tiempo de separar y condenar el tráfico de personas. ${ }^{20}$

Sin embargo, en la era del terrorismo que vivimos, el problema de los polizones no solamente se centra en mecanismos de coordinación administrativa internacional para el tratamiento adecuado en la repatriación de estas personas, sino que tiene en cuenta la factibilidad que los polizones planeen o ejecuten acciones terroristas. Es en este sentido que el Convenio de Facilitación del Tráfico Marítimo Internacional, en vigor desde mayo de 2003, permite a los Estados miembros encarar el problema de una forma más coordinada, entre otros aspectos mediante el estudio periódico de las causas y consecuencias de los casos de polizones.

Desde el ángulo de la seguridad marítima, también el CSM ha aprobado distintos documentos, incluyendo la Circular MSC/Circ896 de junio de 2001 en la cual se adoptan criterios para combatir prácticas opera-

19 Los mecanismos de inscripción y mantenimiento del registro de esta institución - la de mayor tradición y volumen de operación en el tema- puede verse en http://www.lrfairplay.com.

20 Tres años más tarde, la Asamblea General de las Naciones, mediante la Resolución A.25 de noviembre de 2000, adoptó el tratado más importante que en la actualidad existe en la materia, y que se ha convertido en la referencia de acción para los desarrollos de regulación en otros organismos, como la OMI: el Convenio de las Naciones Unidas contra la Delincuencia Organizada Transnacional y los protocolos adjuntos contra la trata de personas, especialmente mujeres y niños; y contra el tráfico de emigrantes por tierra, aire y mar. 
tivas en las embarcaciones que propician el transporte de emigrantes ilegales a bordo de éstas. En efecto, como puede observarse reiteradamente en tráficos de la costa oeste africana a las Islas Canarias ahora, las embarcaciones involucradas en tráficos de emigrantes no suelen reunir las características de equipamiento, dotación o registro necesarias para viajes como los que fatalmente se intentan.

En el terreno del tráfico de drogas, la OMI a través de la asamblea ha evidenciado su compromiso para la prevención y supresión de sustancias psicotrópicas y precursores químicos, cuando son transportados en embarcaciones que sirven tráficos de altura, ello a través de las guías anexas a la Resolución A.872 (20) de noviembre de 1997. Las guías pretenden ofrecer mecanismos prácticos que tengan en cuenta la realidad del problema, incluida la utilización abusiva de gente de mar por parte de mafias. Se desarrollan también mecanismos para las averiguaciones previas que involucren esta categoría de casos.

\section{Instrumentos especiales de reciente edición en la protección marítima} a cargo de OMI: el Código PBIP y el Sistema LRIT

\section{A. El Código PBIP}

Como apunté al inicio de este trabajo, los eventos del 9-11 no solamente expusieron la fragilidad del sistema aeronáutico internacional, sino también la fragilidad de las operaciones náuticas a nivel mundial, con la posible afectación del transporte de pasajeros, la protección del ambiente y el comercio internacional a escala global. Así, tras la firme decisión de la asamblea en noviembre de 2001, instrumentada en la Resolución A.924 (22), se opta por trabajar en todos los frentes, tanto técnicos como legales, para prevenir y suprimir actos terroristas contra las embarcaciones en puerto y en el mar, abordo y en tierra.

Dada la prioridad de la tarea, la asamblea decidió convocar a una conferencia diplomática para diciembre de 2002, en la cual se tomaran todas las medidas pertinentes e integrales de carácter técnico en protección. Al mismo tiempo, liberó fondos importantes para realizar actividades de cooperación técnica en protección marítima en diversos países en vías de desarrollo. La conferencia diplomática tuvo lugar en las instalaciones de la organización del 9 al 13 de diciembre, periodo en que se culminó la 
negociación y adopción del nuevo capítulo XI-2 del Convenio SOLAS y el Código PBIP.

La conferencia diplomática también adoptó enmiendas a otras disposiciones del Convenio SOLAS para acelerar la implantación de las prescripciones relativas a la instalación de sistemas de identificación automática, así como nuevas reglas relativas al marcado del número de identificación del buque y a la obligación de llevar un registro sinóptico continuo en los buques. La conferencia aprobó asimismo diversas resoluciones, incluidas las relativas a la implantación y revisión del Código PBIP, la cooperación técnica y la colaboración con la Organización Internacional del Trabajo (OIT).

Las disposiciones pretenden estar redactadas de modo que se garantice su compatibilidad con el Convenio Internacional sobre Normas de Formación, Titulación y Guardia para la Gente de Mar 1978/95 (Convenio STCW), el Código Internacional de Gestión de la Seguridad (Código IGS) y el sistema armonizado de reconocimientos y certificación. El Código PBIP está segmentado en dos partes: la parte A está constituida por normas de carácter obligatorio, mientras que la parte $\mathrm{B}$ son orientaciones a los Estados miembros en su implementación. ${ }^{21}$ El Código PBIP tiene cinco objetivos básicos:

a) Establecer un marco internacional que canalice la cooperación entre gobiernos contratantes, organismos gubernamentales, administraciones locales y sectores naviero y portuario, con el fin de detectar las amenazas para la protección y adoptar medidas preventivas contra los sucesos que afecten a la protección de los buques o instalaciones portuarias utilizados para el comercio internacional.

b) Definir las funciones y responsabilidades respectivas de los gobiernos contratantes, los organismos gubernamentales, las administraciones locales y los sectores naviero y portuario, a nivel nacional e internacional, con objeto de garantizar la protección marítima.

c) Garantizar que se recopila e intercambia con prontitud y eficacia información relacionada con la protección.

21 Como está señalado en el punto 9 del preámbulo al Código PBIP, las orientaciones recogidas en la parte $\mathrm{B}$ del código deberán tenerse en cuenta al implantar las disposiciones sobre protección que figuran tanto en el capítulo XI-2 del Convenio SOLAS 1974, como en la parte A del mismo código. Sin embargo, esas orientaciones serán aplicables en mayor o menor medida, según la naturaleza de la instalación portuaria y del buque, del servicio de que se trate y/o de la carga. 
d) Ofrecer una metodología para efectuar evaluaciones de la protección con el fin de contar con planes y procedimientos que permitan reaccionar a los cambios en los niveles de protección.

e) Garantizar la confianza de que se cuenta con medidas de protección marítima adecuadas y proporcionadas.

A partir de estos objetivos, el Código PBIP desarrolla siete prescripciones funcionales básicas: 1) Recopilar y evaluar información sobre las amenazas para la protección marítima e intercambiar dicha información con los gobiernos contratantes interesados; 2) Exigir el mantenimiento de protocolos de comunicación para los buques y las instalaciones portuarias; 3) Evitar el acceso no autorizado a los buques e instalaciones portuarias y a sus zonas restringidas; 4) Evitar la introducción en los buques e instalaciones portuarias de armas no autorizadas, artefactos incendiarios o explosivos; 5) Facilitar los medios para dar la alarma cuando se produzca una amenaza para la protección marítima o un suceso que afecte dicha protección; 6) Exigir planes de protección para el buque y para las instalaciones portuarias basados en evaluaciones de la protección; y 7) Exigir formación, ejercicios y prácticas para garantizar que el personal se familiariza con los planes y procedimientos de protección. ${ }^{22}$

En esencia, el Código PBIP prevé una relación a partir de sujetos clave, instrumentos básicos y niveles de protección; todo ello en una dinámica de gerencia de riesgos. Estos tres elementos, en el contexto de la coordinación estatal de cada Estado miembro, pretenden dar certeza que el sistema de protección marítima de cada país - y a partir de ello de todo el mundo- es lo suficientemente efectivo. Los sujetos clave son el Oficial de Protección del Buque (OPB); el Oficial de la Compañía para la Protección Marítima (OCPM); y el Oficial de Protección de la Instalación Portuaria (OPIP). Los instrumentos básicos están diseñados a partir del objeto de protección; es decir: el Plan de Protección del Buque, y el

22 A partir de las funciones básicas aquí referidas, la obligación básica de cada gobierno contratante radica en establecer los niveles de protección y orientar sobre la forma de protegerse contra los sucesos que afecten a la protección marítima. Ante la gravedad de esta obligación, se discutieron diversos factores a tomar en cuenta por los gobiernos al establecer niveles de protección: a) En qué medida es creíble la información sobre la amenaza; b) En qué medida hay corroboración de la información sobre la amenaza; c) En qué medida la información sobre la amenaza es específica o inminente; d) Las posibles consecuencias del suceso que afecte a la protección marítima. Código PBIP, artículo 4.1. 
Plan de Protección de la Instalación Portuaria. Por último, se cuenta con tres niveles de protección dependiendo del análisis de riesgo.

Así, el OPB es la persona a bordo del buque responsable ante el capitán, designada por la compañía para responder de la protección del buque, incluidos la implantación y el mantenimiento del plan de protección del buque, y para la coordinación con el oficial de la compañía para la protección marítima y con los oficiales de protección de las instalaciones portuarias. El OCPM por su parte, es la persona designada por la compañía para asegurar que se lleva a cabo una evaluación sobre la protección del buque y que el plan de protección del buque se desarrolla, se presenta para su aprobación, y posteriormente se implanta y mantiene, y para la coordinación con los OPIP y los OPB. El OPIP finalmente es la persona designada para asumir la responsabilidad de la elaboración, implantación, revisión y actualización del plan de protección de la instalación portuaria, y para la coordinación con los OPB y con los OCPM.

Como señalaba, el análisis de riesgo inmanente al Código PBIP prevé tres niveles de protección: 1) El nivel en el cual deberán mantenerse las medidas mínimas adecuadas de protección en todo momento; 2) El nivel en el cual deberán mantenerse medidas adecuadas de protección adicionales durante un periodo de tiempo, como resultado de un aumento del riesgo de que ocurra un suceso que afecte la protección marítima; y 3) El nivel en el cual deberán mantenerse más medidas concretas de protección durante un periodo de tiempo limitado cuando sea probable o inminente un suceso que afecte a la protección marítima, aunque no sea posible determinar el blanco concreto.

El ámbito material de validez del Código PBIP incide en cuatro grandes categorías de bienes: a) Los buques de pasaje, incluidas las naves de pasaje y gran velocidad; b) Los buques de carga, incluidas las naves de gran velocidad, de arqueo bruto igual o superior a 500 unidades; c) Las unidades móviles de perforación mar adentro; y d) Las instalaciones portuarias que presten servicio a tales buques dedicados a viajes internacionales. En México, la aplicación del Código PBIP se hizo extensiva a todas las embarcaciones que operan en apoyo a las operaciones de Pemex. Exploración y Producción (PEP) con independencia de su tonelaje. La decisión se tomó por la sensibilidad de la protección en una actividad estratégica para México, como es precisamente la exploratoria y la extractiva. 
La eficacia del Código PBIP — en vigor desde julio de 2004 — solamente se da a través de un adecuado funcionamiento de cada uno de sus eslabones. Es decir, la preparación y certificación necesaria por parte de las autoridades marítimas de los Estados contratantes a los sujetos, la aprobación de los planes de protección, el envío oportuno de los informes a OMI, la cooperación en materia de visitas mutuas y ejercicios; la reingeniería de todo el proceso de los planes de protección, los niveles de riesgo, etcétera.

En México, la facultad de implementación del Código PBIP bajo la supervisión de la Secretaría de Comunicaciones y Transportes (SCT) fue delegada por acuerdo administrativo al Fideicomiso de Formación y Capacitación para el Personal de la Marina Mercante Nacional (Fidena), quien es la estructura administrativa que coordina a las escuelas náuticas mercantes del país. Sin duda, el Código PBIP ha sido de utilidad internacional, no solamente en la prevención específica de actos terroristas, sino incluso en la disminución de la piratería, en la disminución de polizones, en el robo de equipos; y en general en la protección genérica de buques e instalaciones portuarias; y las personas y bienes a ellos relacionadas. ${ }^{23}$

\section{B. El Sistema LRIT}

Uno de los avances más recientes en protección marítima fue el paso dado por el Comité de Seguridad Marítima (CSM) de OMI en mayo de 2006, respecto a uno de los mecanismos técnicos más certeros para monitorear embarcaciones a distancia y así determinar el riesgo que puedan implicar: el Sistema LRIT. Las nuevas reglas están incluidas en el capítulo V del Convenio SOLAS referido a la seguridad en la navegación; a través del cual el LRIT tendrá carácter obligatorio para las siguientes embarcaciones en rutas internacionales: embarcaciones a partir de 300 TRB

23 Entre los documentos más importantes respecto a las facultades delegadas a Fidena en material del Código PBIP se encuentran: a) el Acuerdo publicado en el DFO del 11 de febrero de 2004 en el cual se dan a conocer las Enmiendas a SOLAS y el Código PBIP mismo, así como las facultades para la implementación; y b) la Circular 500.012 del 12 de enero de 2004 en que la CGPMM informa sobre el programa derivado del código y las funciones de Fidena. Mas de una docena de circulares y acuerdos adicionales se han generado en nuestro país a partir de la implementación. La SCT mantiene además el contacto necesario con la OMI para la actualización de los datos a que está obligado reportar en esta materia. Véase www.fidena.gob.mx. 
dedicadas a pasaje y/o carga incluidas las naves de gran velocidad, así como las unidades móviles de perforación mar adentro. ${ }^{24}$

El Sistema LRIT establece un acuerdo multilateral para compartir información derivada de éste para propósitos de protección, así como de búsqueda y salvamento, entre los Estados miembros del Convenio SOLAS. Mantiene el derecho del Estado de bandera para proteger información sobre las embarcaciones que enarbolen su bandera; al tiempo que permite a los Estados ribereños tener acceso a la información respecto a las embarcaciones que naveguen más allá de sus costas. Es importante tener en cuenta que el espíritu de la enmienda al Convenio SOLAS relativo al Sistema LRIT se centra en no crear derecho alguno a favor de los Estados sobre embarcaciones que los ya establecidos en los tratados internacionales en vigor, incluyendo la Convemar. Tampoco debe entenderse que alteren o afecten derecho alguno, normas sobre jurisdicción, deberes y obligaciones de los Estados respecto a Convemar.

En esencia, bajo el Sistema LRIT, la información que las embarcaciones estarán obligadas a transmitir es su identidad, ubicación, así como la fecha y hora de su posición. La diferencia básica con el Sistema de Identificación Automática (SIA) acordado también por OMI desde el 2003 y el Sistema LRIT, además del rango, es que mientras el Sistema SIA es en realidad un sistema de difusión general, la información derivada del Sistema LRIT será proporcionada exclusivamente a los destinatarios que tengan derecho a ello - los Estados miembros del Convenio SOLAS - , con el obvio deber de confidencialidad. En este sentido, los Estados miembros tendrán derecho a que les sea proporcionada la información LRIT de embarcaciones que naveguen a una distancia que no exceda de 1000 millas náuticas más allá de sus costas.

Las inclusiones del LRIT en el Convenio SOLAS prevén una fase de implementación agendada para embarcaciones construidas antes de la entrada en vigor del propio sistema; esto es el 1o. de enero del 2008, así como una excepción para embarcaciones que operen exclusivamente en el área marina A1, pues estas embarcaciones cuentan ya con el Sistema SIA. Las normas del LRIT identifican también cuáles autoridades especí-

24 Un gráfico de la arquitectura del Sistema LRIT, puede ser visto en la sección sobre protección dentro del área de seguridad de la navegación de la página web de la OMI: www.imo.org. 
ficamente están legitimadas a tener acceso a la información derivada de este nuevo mecanismo.

\author{
IV. LOS INSTRUMENTOS SUA DE OCTUBRE DE 2005 \\ Y EL COMBATE AL TERRORISMO INTERNACIONAL. CLAROSCUROS \\ DE LA NEGOCIACIÓN Y CONSECUENCIAS DEL NUEVO RÉGIMEN
}

\title{
1. Consideraciones generales
}

Como ya antes sugería, una de las tareas más importantes de la OMI en materia de protección ha sido la negociación y adopción del Convenio SUA y del Protocolo SUA en octubre de 2005. La tarea fue asignada al Comité Legal de la organización como respuesta a la Resolución A 924 (22) de la asamblea de noviembre de 2001. La negociación estuvo a cargo de un grupo de trabajo del propio Comité Legal de OMI, integrado por aproximadamente treinta países, y presidido por Linda Jacobson, alta funcionaria del Departamento de Estado y jefa de la Delegación de Estados Unidos de América (EUA) durante parte de la conferencia diplomática de otoño de 2005.

Desde luego, EUA, como impulsor de todas las iniciativas en materia de protección a nivel internacional generadas a partir del 9-11, fue, desde la formación misma del grupo de trabajo, la delegación más activa tanto en la elaboración de proyectos preliminares de redacción, como en la negociación formal en el foro y en el cabildeo bilateral, regional e internacional.

Más aún, la ratificación expedita de los instrumentos SUA es uno de los puntos prioritarios en las agendas bilaterales de EUA con diversos actores relevantes en el ámbito marítimo. De hecho, un esquema relativamente parecido al de los instrumentos SUA de 2005 lo tiene ya suscrito EUA desde hace algunos años, mediante memorandos de entendimiento con jurisdicciones clave de registro abierto, entre las que destacan Panamá y Liberia, los dos más grandes registros abiertos a nivel internacional. ${ }^{25}$

25 Los memorandos celebrados son sustancialmente amplios a favor de las facultades de inspección de las autoridades estadounidenses. Según se discutió durante las negociaciones, en las operaciones al amparo de estos memorandos, incluso se acuerda la cesión de jurisdicción del país de registro abierto (Panamá o Liberia) a favor de EUA 
El grupo de trabajo operó tanto como grupo por correspondencia, como grupo inter-sesiones e incluso, dentro de las reuniones del Comité Legal del periodo de gestación del texto definitivo. El primer proyecto presentado por el grupo al Comité Legal de OMI fue en octubre de 2002, a partir de un borrador originalmente producido por la delegación de EUA Desde entonces, se intensificó la actividad a un grado tal que algunas de las sesiones de 2004 y 2005 se extendieron con el fin de avanzar en las negociaciones.

Si bien es cierto que los Convenios SUA de 1988 han sido de muy escasa utilización por los Estados parte, son sin duda alguna una mancuerna de alta consideración en la comunidad internacional. Esta afirmación la evidencia el estado de ratificaciones de estos instrumentos: más de cien. Además, la nutrida participación de las delegaciones durante la negociación desde el 2002, así como la todavía más copiosa reunión de funcionarios públicos y asesores durante la conferencia diplomática, evidencian la prioridad de los instrumentos en el 2005.

Como es natural, los activos miembros del servicio exterior de EUA tienen el mérito de haber hecho lo posible para elevar la tasa de ratificación de los instrumentos SUA de 1988, durante el periodo de negociaciones para su enmienda hasta la conferencia diplomática misma. Se espera que esta eficiencia del Departamento de Estado continúe a nivel bilateral con el ánimo de fomentar la expedita ratificación de los nuevos instrumentos.

Una primera aproximación a los instrumentos SUA 2005 consiste en que deben ser vistos de modo complementario al Código PBIP —en pleno vigor desde julio de 2004 - y del Sistema LRIT — que estará en vigor desde enero de 2008 - . Los tres instrumentos constituyen las herramientas técnicas y jurídicas más completas internacionalmente en la lucha contra el terrorismo marítimo. Desde luego, ni las mejores herramientas técnicas y legales son suficientes para prevenir o incluso, para contrarrestar sustancialmente los efectos de un ataque terrorista bien planeado y ejecutado.

Con ello, las personas, el buque y la carga se rigen por la legislación de EUA en materia de terrorismo; con la gravedad $-\mathrm{y}$ posibles excesos - que esto supone para todos los embarcados. La información relevante en materia de protección en cada uno de los dos registros abiertos aludidos puede estudiarse en: www.segumar.com (Panamá) y www.lis cr.com (Liberia). 
Los instrumentos SUA de 1988 regulan el embargo o aseguramiento, la detención e incluso la extradición de los presuntos delincuentes en la comisión de una serie de ilícitos penales cometidos abordo. Sin embargo, dadas las características del terrorismo internacional del siglo XXI, los tipos delictivos previstos en los convenios de 1988 parecieron demasiado limitados a juicio de EUA y el grupo de trabajo. En efecto, las amenazas terroristas, mediante el uso de armas o material biológico, químico o nuclear, naturalmente no fueron previstas en la redacción de los convenios de referencia.

Un rasgo más de la falta de eficacia de los Convenios SUA de 1988 ante la realidad actual es la falta de facultades expresas y claras para que funcionarios de terceros países puedan embarcarse en aguas internacionales en buques que enarbolan la bandera de un tercer Estado, ya sea para inspeccionar, o bien, en ciertos casos, incluso detener a presuntos terroristas y asegurar armas o materiales a ser usados con tales fines; amén de asistir a embarcaciones que se encuentren bajo los efectos de un ataque terrorista.

Es interesante tener en cuenta también de modo preliminar que, por la dificultad ya experimentada en otros foros internacionales, no existe en los instrumentos SUA de 2005 definición alguna, ni referencia concisa al término "terrorismo" o "terrorista". Al ser protocolos de enmienda y no tratados internacionales de nuevo cuño se ha mantenido la referencia a "actos ilícitos contra la seguridad", cuando técnicamente las especies de conductas delictivas están referidas a lo que en sentido genérico puede entenderse ahora como actos terroristas. La nota común para entender la descripción del tipo es entonces el llamado "motivo terrorista", aunque valga advertir que la exigencia de éste no se extiende necesariamente en cada una de las especies delictivas, según detallaré líneas abajo. $^{26}$

26 Véase Saul, Ben, “Reasons for Defining and Criminalizing 'Terrorism' in International Law", Anuario Mexicano de Derecho Internacional, vol. VI, 2006. La no definición del terrorismo en los instrumentos SUA de 2005 tiene en cierta medida razones políticas y de conveniencia práctica para los Estados que con mayor frecuencia ejercen actos de autoridad contra el terrorismo en el ámbito internacional, entre los cuales, por supuesto, destaca EUA. Así, un cierto margen discrecional para que el operador estadounidense actúe es un elemento conveniente en toda negociación para EUA. El autor de referencia formula un interesante análisis sobre este tema, en donde concluye, entre otros aspectos, que las exageradas ambiciones inherentes a los tratados 
Un elemento más que convalida la naturaleza claramente anti-terrorista de los instrumentos SUA de 2005, a pesar de la falta de una definición expresa, es la técnica de incorporación por referencia a una serie de tratados explícitamente anti-terroristas. Como ilustración de ello: el Convenio Internacional para la Represión de los Atentados Cometidos con Bombas, aprobado por la Asamblea General de la ONU en diciembre de 1997; así como el Convenio Internacional para la Represión de la Financiación de Terrorismo, aprobado también por la Asamblea General de la ONU en diciembre de 1999.

Las enmiendas a cada uno de los dos instrumentos originales (1988) y a su nueva versión a partir del 2005 —es decir al Convenio SUA y al Protocolo SUA sobre Plataformas Fijas - son mutatis mutandi, uniformes. Es por ello que el protocolo relativo a plataformas únicamente incluye los cambios por referencia al convenio sobre buques, en el cual se centró el debate y la redacción íntegra. Ahora bien, como adelante comentaré con mayor detalle, los protocolos contienen básicamente dos categorías de enmiendas.

La primera categoría está referida en el artículo 3o., en el cual se listan los subtipos delictivos. La segunda categoría introduce normas totalmente nuevas a través de las cuales se establecen tanto derechos sustantivos como procedimientos a ser incoados con relación al embarque en alta mar de un barco mercante extranjero, por parte de oficiales operativos de un tercer Estado.

Con este contexto de por medio, a continuación formularé algunos comentarios a algunas de las normas más relevantes en ambas categorías. Al hacerlo, tendré en cuenta tanto el texto definitivo, la opinión de diversas delegaciones a lo largo del proceso de negociación y algunas consideraciones desde una perspectiva mexicana.

\section{Normas relevantes}

La tipificación penal del transporte de material de uso dual. Uno de los temas de mayor controversia a lo largo de las negociaciones del grupo fue la del uso dual del material transportado. El texto definitivo quedó consolidado con la siguiente redacción:

sectoriales serían clarificadas por una respuesta más calibrada, diferenciando la violencia pública de la privada. 
Comete delito en el sentido del presente convenio toda persona que ilícita e intencionadamente... transporte a bordo de un buque... cualquier equipo, materiales o software o tecnología conexa que contribuya de forma importante al proyecto, fabricación o envío de un arma BQN con la intención de que se use para ese fin. ${ }^{27}$

Si bien la inclusión como delito de una conducta consistente en el transporte de materiales de doble uso y de tecnología conexa fue decidido por el Comité Legal desde octubre de 2004, lo cierto es que las disparidades de opinión en cuanto a qué tipo de tratamiento dar al uso dual, eran profundas. En efecto, la apertura francamente extrema del tipo delictivo no solamente puede convertir al convenio en una especie de patente de corso para la comisión de posibles arbitrariedades de los oficiales que efectúen inspecciones en alta mar, sino que incluso puede generar en esta etapa previa problemas de carácter constitucional en distintas jurisdicciones que por ello se vean impedidas para ratificar el instrumento, aun con los exhortos reiterados de países como EUA. ${ }^{28}$

A partir de un consenso relativo en el Comité Legal por continuar trabajando bajo la premisa de la inclusión del uso dual, el grupo examinó diversos enfoques alternativos, incluyendo: la referencia a listas de materiales y equipos, incorporadas en otros tratados internacionales; regímenes de concesiones; licencias de exportación e importación, etcétera. La falta de uniformidad en estas aproximaciones frenó cualquier posibilidad de circunscribir de forma nominativa al uso dual.

Ahora bien, con respecto a la frase - varias veces alterada - "contribuya de forma importante", algunas delegaciones opinaron que esto debería ser determinado por el Estado de bandera. No obstante, otras eran

27 Convenio SUA 2005, artículo 3bis 1 b) iv. De acuerdo al artículo 1.1 d) del convenio se entiende por "arma BQN" las tres categorías de armas cuya definición ha sido desarrollada en los convenios directamente ligados a los Protocolos SUA: armas biológicas, armas químicas y armas nucleares, incluyendo los precursores respectivos. Desde luego, cada categoría incluye una amplia lista de especies y algunas excepciones.

28 La prioridad del gobierno de EUA en los instrumentos SUA para mantener un nivel discrecional amplio a partir del cual pueda realizar las visitas de inspección a las embarcaciones e interpretar, de acuerdo con sus propias consideraciones de seguridad nacional, la naturaleza terrorista de un cierto transporte, es expuesta entre otros autores por Crook, John, "United States Supports New Protocols Directed Against Use of Ships in Terrorism and Proliferation of Waepons of Mass Destruction", American Journal of International Law, núm. 100-224, enero de 2006. 
de la impresión que esto debería ser determinado por los tribunales ante los que se presentase el caso. A otras incluso, les preocupaba que ocurrieran casos en que dos Estados diferentes pudieran hacer interpretaciones diferentes e incluso contradictorias. Este es el posible escenario del Estado de bandera y el Estado solicitante de la visita; o bien el Estado en que quede incoado el proceso. Desde luego, uno de los aspectos más criticados sobre este tema ha sido la ausencia de la intención o motivo terrorista.

Esta falta de vinculación a un motivo terrorista generará muy probablemente ajustes en la forma de efectuar operaciones de transporte y logísticas en general, toda vez que el solo hecho de transportar - elemento objetivo- objetos que puedieran ser utilizados con relación a armas BQN incluso sin el conocimiento de su propósito funcional - elemento subjetivo - es suficiente para que la conducta surta el tipo delictivo previsto, y sea por tanto, sancionable. A la gravedad en el potencial uso arbitrario de un tipo tan abierto debe aunarse el hecho técnico de la operación. Es decir, ¿qué es transporte para efectos de los Protocolos SUA? "De acuerdo al artículo 1.1 b) del convenio, 'por transporte se entenderá iniciar u organizar el movimiento de una persona o artículo, o ejercer su control efectivo incluida la autoridad decisoria"'.

Así como en el caso del uso dual, el único requisito de la definición es de carácter objetivo. Esto es, no tiene en cuenta la intencionalidad de la operación del transporte; sino todos los actos técnicos, económicos y jurídicos vinculados al traslado por todos los sujetos que en él intervienen. En este sentido, el elemento subjetivo, conocido como la intención terrorista, no está establecido como condición necesaria para cada uno de los subtipos delictivos que prevé el convenio.

Las deficiencias y consecuencias relacionadas respecto al "uso dual" y al "transporte" fueron expuestas reiteradamente durante varias sesiones por diversas delegaciones - incluida la mexicana - sin que la dinámica de las negociaciones, fuertemente catalizada por la opinión altamente imperativa de EUA, permitiera efectuar las correcciones adecuadas. En una de sus múltiples intervenciones sobre el particular, la delegación de la India expone con claridad y sencillez el problema: ${ }^{29}$ 
Haremos una vez más hincapié que toda definición de la expresión "transporte" ha de ser sin ambigüedades y ha de tener como objetivo esencial evitar que se enjuicie a gente de mar inocente, así como a participantes igualmente inocentes en el conjunto de la cadena logística, quienes es posible que sin conocimiento y sin la menor intención, puedan facilitar una transacción o el trasporte de un artículo que en el marco del convenio está prohibido o está sujeto a controles.

Los límites constitucionales, tanto en México como - seguramente - en muchas otras jurisdicciones respecto a tipos penales abiertos, se harán patentes, al momento en que los instrumentos SUA sean remitidos para aprobación senatorial. Como bien indica una tesis jurisprudencial reciente — de 2003 - en nuestro país sobre el tema de los tipos abiertos:

Debe aclararse que conforme a la dogmática jurídica un tipo penal abierto implicaría la ambigüedad de la descripción a grado tal que fuese la autoridad judicial la encargada, en lo absoluto de cerrar o concluir la descripción típica, supuesto que resultaría incluso incompatible con un sistema o Estado de derecho en el que se respete el principio de exacta aplicación de la ley penal (nullum crimen sine lege). ${ }^{30}$

El tipo delictivo consistente en el transporte de un objeto de uso dual, vinculado a la definición misma de transporte hace, como he intentado argumentar en estas líneas, una conducta penal típica verdaderamente abierta, en donde en la práctica, todo sujeto directa o indirectamente relacionado con cualquier eslabón de la cadena logística y respecto a cualquier material transportado es presuntamente responsable.

En este contexto, será interesante advertir cuál es el criterio que el Senado de la República adopte de acuerdo al artículo 76, fracción I, de la Constitución federal, una vez que ejerza su facultad exclusiva para aprobar o no los instrumentos SUA, en el ámbito de los principios constitucionales que deben regir su facultad de aprobación. De ser aprobados, y una vez depositado el instrumento de ratificación ante la OMI, será también de gran importancia conocer la eventual resolución que formule la SCJN, luego de un caso de aplicación del convenio.

30 Si bien se trata de una tesis aislada, ésta sigue claramente el sentido de la jurisprudencia definida en la materia en otras épocas. Véase Segundo Tribunal Colegiado en Materia Penal del Segundo Circuito, Amparo Directo 519/2002, 7 de febrero de 2003, tesis II, 2o., p. 97. 
La lista de conductas señalada a lo largo de los artículos 3 bis, 3 ter y 3 quarter, agrupa respectivamente tres categorías: 1) La utilización del buque como arma; así como la transportación en él de BQN, explosivos y materiales relacionados; 2) La transportación de personas implicadas en cualquiera de las otras dos categorías de delitos citados; y 3) La coparticipación y la tentativa de comisión de las conductas penales descritas. Lo que he expuesto en torno a los problemas de apertura del tipo penal es aplicable a todas las especies de cada una de las tres categorías a las que he aludido.

\section{El procedimiento de visitas de inspección y las cuestiones de jurisdicción relacionadas}

Como ya he anunciado, entre los elementos innovadores de los instrumentos SUA de 2005 se encuentra una amplia delegación de facultades del Estado de la bandera al Estado que ejerce la visita, que a pesar de no estar definido, se conoce en general - según he referido antescomo el Estado solicitante. Desde luego, solamente los Estados que tengan una armada relevante y ánimo de control internacional tendrán la capacidad y decisión de ejercer visitas de inspección de modo sistémico. En este sentido, EUA será muy probablemente el Estado solicitante por antonomasia. En términos generales, el procedimiento de visitas de inspección es el siguiente:

a) Cuando quiera que los agentes de la autoridad $u$ otros funcionarios autorizados del Estado solicitante encuentren un buque que enarbole el pabellón o muestre marcas de matriculación de otro Estado parte que esté fuera del mar territorial de cualquier Estado, y el Estado solicitante tenga motivos razonables para sospechar que el buque o una persona a bordo ha participado, participa o va a participar en la comisión de alguno de los delitos establecidos en el protocolo, y el Estado solicitante desee visitar el buque tendrá que realizar lo siguiente: 1) Solicitar la confirmación de nacionalidad al Estado de pabellón; y 2) Si se confirma la nacionalidad, el Estado solicitante debe pedir al Estado de pabellón autorización para realizar una visita y adoptar las medidas apropiadas con respecto al buque, entre las que pueden estar interceptar, visitar y registrar el buque, su carga y las personas a bordo e interrogar a las personas a bordo con el fin de determinar si se ha cometido o se va a cometer alguno de los señalados delitos. 
b) Ahora bien, las facultades del Estado de pabellón a partir de lo anterior, son las siguientes: 1) Autorizar al Estado solicitante a realizar una visita y a adoptar las medidas que sean oportunas; o 2) Hacer que sus propios agentes de la autoridad $u$ otros funcionarios realicen la visita y el registro; o 3) Realizar la visita y el registro junto con el Estado solicitante, pudiendo imponer condiciones para ello; o 4) Rehusar la autorización de la visita y el registro.

c) A partir de la decisión que tome el Estado de pabellón, y en su caso, si como resultado de las visitas realizadas se encuentran pruebas de la comisión de alguno de los delitos tipificados en los protocolos, el Estado de pabellón podrá autorizar al Estado solicitante para retener el buque, la carga y las personas a bordo, a la espera de recibir las instrucciones dictadas por el Estado de pabellón sobre qué es lo que ha de hacerse. Las partes tienen el deber de informarse sin dilación.

d) El Estado de pabellón podrá supeditar la autorización, incluida la obtención de información adicional del Estado solicitante y las condiciones relativas a la responsabilidad acerca de las medidas que han de adoptarse y el ámbito de éstas. No podrán adoptarse medidas adicionales sin la autorización expresa del Estado de pabellón, excepto cuando sea necesario para mitigar riesgos inminentes para la vida de las personas o las medidas se deriven de los acuerdos bilaterales o multilaterales pertinentes.

e) Cuando se realice una visita, le corresponde al Estado de pabellón ejercer jurisdicción sobre el buque detenido, la carga y otros bienes, y las personas a bordo, incluido el apresamiento, la confiscación, el embargo y la acción penal. No obstante, el Estado de pabellón de conformidad con su Constitución y demás legislación, podrá dar su consentimiento a que otro Estado ejerza su jurisdicción.

Ante un ámbito tan amplio de posibles facultades soberanas delegadas del Estado de pabellón al Estado solicitante, una mayoría de delegaciones — incluida la mexicana - intentaron establecer un abanico importante de salvaguardas, además de los parámetros de la responsabilidad indemnizatoria, a raíz de operaciones en que el Estado solicitante se exceda en el uso de la fuerza; o bien no sea una operación debidamente autorizada. En este sentido, algunas de las salvaguardas son:

a) Tener en cuenta la necesidad de no poner en peligro la seguridad de la vida humana en el mar. 
b) Velar porque las personas a bordo sean tratadas de modo que se preserve su dignidad humana de acuerdo al derecho internacional, incluida la legislación internacional sobre derechos humanos.

c) Velar porque las visitas y registros se hagan de conformidad con el derecho internacional aplicable.

d) Tener debidamente en cuenta la seguridad y la protección del buque y de su carga.

e) Velar porque las medidas adoptadas con respecto al buque o su carga sean ecológicamente razonables.

f) Asegurarse que los inculpados de los delitos señalados en el protocolo disfruten de la protección en materia de extradición de acuerdo al tratado en la materia que se tenga; o bien de acuerdo a las normas del propio protocolo.

g) Asegurarse que el capitán del buque sea notificado de la intención de realizar la visita, así como que tenga la oportunidad de contactar con el propietario del buque y el Estado de bandera, a la mayor brevedad.

h) Hacer lo posible para evitar la demora o inmovilización indebida del buque.

Durante las negociaciones del Convenio SUA 2005, la delegación mexicana encabezó la propuesta en materia de indemnización a favor de los tripulantes, de los titulares de la embarcación y de la carga cuando: 1) Resulten infundados los motivos para la adopción de las medidas adoptadas en la operación; o bien 2) Dichas medidas sea ilícitas o, a la luz de la información disponible, excedan de las que sean razonablemente necesarias. ${ }^{31}$

31 La responsabilidad patrimonial del Estado ante eventos de naturaleza internacional es un tema que, aunque ha sido explorado ampliamente en casuística y doctrina, requerirá de un análisis extensivo a partir de lo que ha quedado expresamente ordenado por los instrumentos SUA. Aunque limitado y de no muy afortunada redacción - derivada de la complejidad misma de la negociación del punto- el aspecto de la indemnización es uno de los pocos elementos claramente rescatables del convenio a favor de los particulares, especialmente de los tripulantes. En ello estuvieron preocupados tanto los países que normalmente actuarán sólo como Estado de bandera, como las ONG empresariales y sociales (ICS e ITF, principalmente); quienes desde el principio apoyaron con fuerza el tema impulsado por nuestro país. En cuanto a una reiterada valoración de la responsabilidad estatal, véase Ávalos, Roxana, "Responsabilidad del Estado por hecho internacionalmente ilícito del Estado. ¿Más de 40 años de labor de la Comisión de Derecho Internacional para nada?", Anuario Mexicano de Derecho Internacional, vol. VI, 2006. 
Se logró adicionar a la norma que aquí se comenta que "los Estados partes dispondrán recursos efectivos con respecto a tales daños, perjuicios o pérdidas". Cabe señalar además que para el caso de afectación a tripulantes, el concepto de daños y perjuicios no quedó restringido al ámbito de las lesiones físicas o incluso la muerte, sino como claramente se encuentra en la versión inglesa del Convenio a harm, término de connotación extensiva al ámbito económico integral de la víctima del exceso o la ilicitud del Estado solicitante.

Sobre el tema se planteó una natural contradicción de intereses: los posibles Estados solicitantes (principalmente EUA) abogaban porque las indemnizaciones arriba descritas fueran efectuadas exclusivamente por los Estados de bandera, en virtud de que serán ellos los que confirmen la nacionalidad y autoricen al Estado solicitante para que sus oficiales se embarquen a realizar la visita. Los muchos Estados de bandera - entre ellos México - alegaban a su vez que el cargo de la indemnización fuera cubierto únicamente por los Estados solicitantes, ya que sólo en manos de ellos estará la operación efectiva de cada visita y no podrán tener aquéllos un control real de la operación; con lo cual, quien causaría el daño sería, en efecto, el Estado solicitante.

Tras diversas rondas de sesiones, México propuso un compromiso que fue aceptado por el grupo de trabajo y que trascendió más tarde a la conferencia diplomática; por lo que está ahora plasmado en el artículo 8 bis 10 b). Si bien la redacción podría parecer confusa, el sentido de la norma radica en que un tripulante, consignatario de la carga o armador del barco - o los aseguradores subrogados en cualquiera de los casosafectado por la ilicitud o exceso de la visita y consecuencias de ésta, pueda demandar al Estado solicitante (por ejemplo EUA) cuando el Estado de bandera exclusivamente haya confirmado la nacionalidad del buque y a autorizado al Estado solicitante a realizar la operación. Por supuesto, nada obsta para que el actor pueda al propio tiempo incoar acción en contra del Estado de bandera también.

\section{El tratamiento de las normas en materia de no proliferación nuclear. Posiciones disidentes}

Uno de los temas de más acalorado disenso tanto en el grupo como en la conferencia diplomática fue el de la extensión de obligaciones del Tratado de No Proliferación de Armas Nucleares de 1968 (TNP) al ámbi- 
to de aplicación del Convenio SUA. Países como India, Pakistán, Israel e Irán, mostraron su total oposición a que OMI mezclara conceptos respecto de los cuales solamente la Agencia Internacional de Energía (AIE) es competente. Si bien no participó activamente en las negociaciones o posicionamientos expresos, debe entenderse que la posición de Corea del Norte es similar a la de los países disidentes señalados. ${ }^{32}$

Estos países alegaron con vehemencia a lo largo del proceso de negociación y adopción que, en contradicción con el derecho internacional, se ha criminalizado mediante el Convenio SUA las aplicaciones pacíficas de la energía nuclear, que ni siquiera la AIE ha antes tipificado como delito. En este sentido, se manifestaron reacias a restringir sus derechos soberanos para transportar material nuclear o de uso nuclear dual, así como cualquiera otra tecnología para ser utilizada en proyectos civiles.

Más aún, se ha criticado el trato discriminatorio entre los Estados nucleares que son miembros del TNP, respecto a aquellos que no lo son. En efecto, de acuerdo al artículo 3 bis 2, no constituye delito transportar material o artículos, en tanto esté conexo con un arma nuclear u otro dispositivo nuclear explosivo, si ese artículo o material se transporta desde o hacia el territorio de un Estado parte en el NPT; o bien se transporta de otro modo bajo su control. Esta aparente laxitud de la norma para los Estados nucleares miembros de TNP (EUA, Rusia, Francia, China y Reino Unido) está limitada a dos posibles condiciones:

a) Que la transferencia o la recepción resultantes, incluidas las internas dentro de un Estado, del artículo o del material no sean contrarias a las obligaciones de dicho Estado parte de conformidad con el TNP.

b) Que cuando el artículo o el material esté destinado al sistema vector de un arma nuclear u otro dispositivo nuclear explosivo de un Estado parte en el TNP, la tenencia de tal arma o dispositivo no sea contraria a las obligaciones de ese Estado parte de conformidad con el Convenio SUA.

Si bien es cierto que la argumentación de derecho internacional de los países disidentes podría encontrarse con cierto mérito, la verdad es

32 Sobre algunos de los aspectos más estrechamente vinculados del TNP en el ámbito de los instrumentos SUA de 2005, véase Crook, John, "U. S. Concerns about Declining Effectiveness of Nonproliferation Regime", American Journal of International Law, núm. 99-917, octubre de 2005; Harrington, John, "Arms Control and Disarmament”, The International Lawyer, num. 35-579, verano de 2001. 
que el resto de los Estados participantes en la conferencia diplomática consideraron que por una parte, la lucha contra el terrorismo no podría dejar de cubrir el transporte de material nuclear y que, en todo caso, los Estados disidentes podrían no ratificar el Convenio SUA y decidir lo más conveniente para sus propósitos.

Desde luego, el transporte de material nuclear para los Estados Nucleares no Miembros del TNP tendrá que ser hecho bajo sus propias banderas, si pretenden evitar la aplicación del Convenio SUA. En este contexto, resulta interesante observar dos extractos representativos de India y de Pakistán — países por demás enfrentados bélicamente- sobre su posición en cuanto a la alegada violación de derecho internacional y actuación discriminatoria respecto a los Estados no Miembros del TNP:

La India comparte plenamente el objetivo e velar por la seguridad de la navegación marítima frente a la amenaza del terrorismo, en particular ante la posibilidad de que los terroristas adquieran o utilicen armas de destrucción masiva. Ello no obstante, la India se ha visto obligada a plantear sus objeciones, ya que algunas de las enmiendas propuestas incorporan principios derivados del Tratado sobre la No Proliferación de las Armas Nucleares, del cual no es parte. A juicio de la India, todo régimen convencional es aplicable solamente a los Estados partes interesados y no puede extenderse a fin de abarcar a Estados no partes ni interpretarse de forma que se preste para tal propósito (Declaración India).

Dado que Pakistán es un Estado nuclear y que, además no es parte en el Tratado sobre la No Proliferación de las Armas Nucleares, no puede aceptar las obligaciones relativas a dicho tratado que se recogen en las enmiendas del convenio. Pakistán ha señalado continuamente la necesidad de asegurarse de que las propuestas de enmiendas al Convenio SUA no sean discriminatorias y que confieran idénticos derechos y obligaciones a todos los Estados partes. Ningún instrumento internacional que sea aplicable a los Estados partes se puede extender a los Estados que no son partes. Y cualquier enmienda que apunte a la restricción del derecho de los Estados que no son partes en el tratado al uso pacífico de la tecnología nuclear es discriminatoria y, por consiguiente, no es aceptable para Pakistán (Declaración Pakistán).

\section{COMENTARIOS FINALES}

La importancia y compromiso por la protección marítima no debe generar controversia alguna, en tanto ésta se encuentre acompañada de lí- 
mites pertinentes a la autoridad. El vehículo por excelencia de limitación a la autoridad es la ley, sea ésta de origen nacional o universal. Por ello, contar con instrumentos jurídicos internacionales suficientemente balanceados no solamente genera certeza, sino que favorece el consenso para la vinculación expedita al tratado en cuestión.

Si bien los instrumentos SUA de octubre de 2005 tienen su causa en un fenómeno real y terrible a combatir - el terrorismo internacionalno fueron negociados ni redactados de forma tal que ofrezcan el más alto grado de confianza a individuos e instituciones. La amplitud en los diversos ámbitos de validez de sus normas, la falta de definiciones precisas y la apertura de los tipos delictivos previstos propician una seria duda sobre la constitucionalidad de los dos nuevos tratados. En ese sentido, el Senado de la República tendrá que ser cuidadoso al analizar la posible aprobación de los instrumentos, para su posterior ratificación ante la OMI a cargo del presidente de la república, mediante la cancillería.

Ahora bien, en el supuesto de que nuestros órganos de poder consideren que el tratado no supone por sí mismo violaciones a la Constitución federal, me parece que en su implementación en México, como Estado de bandera, el Ejecutivo federal y particularmente la Secretaría de Comunicaciones y Transportes, la Secretaría de Marina y la Secretaría de Relaciones Exteriores deberán coordinarse con todo detalle y eficacia para que, ante la probable autorización a un Estado solicitante, condicionen la visita de inspección a la indemnización total $-\mathrm{y}$ garantizada por algún mecanismo idóneo- por parte exclusiva del Estado solicitante, en caso de ilicitud de la visita por cualquier razón, o bien, por abuso en el uso de la fuerza de la autoridad de los oficiales extranjeros embarcados en un buque de bandera mexicana, en perjuicio de los tripulantes, la carga o el buque mismo.

La gravedad de la situación de posibles abusos de autoridad por parte de los oficiales del Estado solicitante va más allá todavía. Como es evidente, tanto prácticamente la totalidad del comercio exterior por vía marítima de México, como la inmensa mayoría del apoyo náutico a Petróleos Mexicanos se realiza mediante embarcaciones de bandera extranjera; la mayoría de las cuales se encuentran en registros abiertos -el término formal del siglo XXI para las viejas conocidas banderas de conveniencia-, cuyos países muy probablemente cederán su jurisdicción total o parcialmente a favor del Estado solicitante. 
Así, no solamente el comercio exterior y el desarrollo petrolero está comprometido en caso de abusos de autoridad del Estado solicitante, sino incluso la vida e integridad física de los tripulantes de nacionalidad mexicana que se encuentren a bordo de embarcaciones de pabellones de Estados parte de los instrumentos SUA 2005.

En este contexto, si bien defiendo las limitaciones necesarias a la libertad de navegación, con el propósito de garantizar el respeto al ambiente marino, a la seguridad de la vida humana en el mar y a la protección integral de personas y bienes en el mar y relacionados a éste, no comulgo bajo ningún concepto con la idea que estas justificadas limitaciones se tejan bajo presiones prepotentes, en un afán por privilegiar el fortalecimiento - cada vez más peligroso - de Estados que, so pretexto de encabezar la lucha contra el terrorismo internacional se han convertido en violadores institucionales de los derechos humanos de miles de personas inocentes, al cobijo de la complicidad de la comunidad internacional. 